\title{
Association of liver cirrhosis severity with anemia: does it matter?
}

\author{
Sonal Singh ${ }^{a}$, Manish Manrai ${ }^{b}$, Parvathi V.S ${ }^{b}$, Dharmendra Kumarc, Sharad Srivastavac, Basant Pathak ${ }^{\mathrm{b}}$ \\ Military Hospital Dehradun; Armed Forces Medical College, Pune; Command Hospital, Pune, India
}

\begin{abstract}
Background The etiology of anemia in liver disease is diverse and often multifactorial. Anemia is more severe in advanced stages of liver cirrhosis and can be a predictor of the severity of liver disease.

Methods In this cross-sectional observational study, we included 181 cirrhotic patients with anemia owing to liver cirrhosis and its complications. The population was divided into 2 groups based on the model for end-stage liver disease (MELD) score and the severity of anemia was assessed in the 2 groups. Similarly, hemoglobin levels were assessed in 3 groups based on the Child-Turcotte-Pugh (CTP) classification.

Results There was a statistically significant correlation between CTP class and hemoglobin $(\mathrm{P}<0.001)$, with the lowest hemoglobin levels in CTP C patients. The correlation coefficient between hemoglobin and MELD score was -0.671 and was statistically significant, establishing that hemoglobin levels decrease with increasing severity of liver cirrhosis. Of 58 patients with macrocytosis, $45(77.6 \%)$ had a MELD score of $>12$, whereas only 13 patients $(22.4 \%)$ had a MELD score of $<12$. This difference was statistically significant $(\mathrm{P}<0.0001)$.

Conclusion This study shows that hemoglobin levels decrease with increasing severity of liver disease; thus, this measure can be used in the initial assessment of patients to give a picture of the severity of the disease. A larger prospective trial is needed to establish the use of hemoglobin levels for assessing severity and predicting mortality in patients with liver cirrhosis.
\end{abstract}

Keywords Anemia, liver cirrhosis, model for end-stage liver disease score, macrocytosis, ChildTurcotte-Pugh class

Ann Gastroenterol 2020; 33 (3): 1-5

\section{Introduction}

Anemia is the most common complication of liver cirrhosis and is seen in $75 \%$ of cases [1]. The etiology of anemia in liver disease is diverse and often multifactorial. Common causes include acute and chronic blood loss due to upper gastrointestinal (GI) bleeding, malnutrition, hypersplenism secondary to portal hypertension, and impaired coagulation [2,3]. Alcohol causes anemia by its direct bone

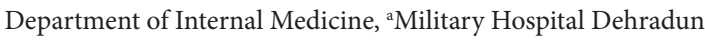
(Sonal Singh); ' Armed Forces Medical College, Pune (Manish Manrai, Parvathi V.S., Basant Pathak); 'Command Hospital, Pune (Dharmendra Kumar, Sharad Srivastava)

Conflict of Interest: None

Correspondence to: Dr Manish Manrai, Department of Internal Medicine, Armed Forces Medical College, Pune 411040, India,

e-mail: manishmanrai@outlook.com

Received 2 December 2019; accepted 9 March 2020; published online 13 April 2020

DOI: https://doi.org/10.20524/aog.2020.0478 marrow toxicity, vitamin $\mathrm{B} 12$ and folate deficiency due to poor oral intake, and intestinal malabsorption. Treatmentrelated anemia is seen in patients with chronic hepatitis $\mathrm{C}$ virus infection receiving ribavirin and interferon. Hepatitisassociated aplastic anemia, characterized by pancytopenia and hypocellular bone marrow, is an entity seen concurrently with or within 6 months of infection with hepatotropic viruses such as hepatitis B, hepatitis C and Epstein-Barr virus [4]. Given the diverse and sometimes multifactorial etiology (alcohol and hepatitis B) of cirrhosis, it is difficult to determine the exact cause of anemia in these groups of patients.

The most common type of anemia encountered in liver cirrhosis is normocytic normochromic anemia, attributable to the chronic inflammatory state [5]. Acute and chronic blood loss from varices, portal hypertensive gastropathy and gastric antral vascular ectasia can give rise to iron-deficiency anemia, in which the picture is one of microcytic hypochromic anemia [6]. Another common hematological abnormality seen in liver cirrhosis is macrocytosis. The causes of macrocytosis in liver cirrhosis are also multifactorial. Vitamin B12 and folate deficiency is also frequently seen in liver cirrhosis, particularly of alcoholic origin, due to malnutrition and intestinal 
malabsorption. However, liver cirrhosis is characteristically associated with round macrocytes [7-9], whereas B12 and folate deficiency show oval macrocytes and hyper-segmented neutrophils on peripheral blood smear (PBS), along with megaloblastic erythropoiesis on bone marrow examination.

The model for end-stage liver disease (MELD) score was designed to assess the prognosis of cirrhotic patients undergoing trans jugular intrahepatic portosystemic shunt [10]. Three variables-bilirubin, creatinine and international normalized ratio (INR) - each of which has an independent impact on survival, are included in the determination of the MELD score. The MELD score has been adopted since 2002 for organ allocation to patients listed for liver transplantation [11]. Lower hemoglobin $(\mathrm{Hb})$ levels are associated with higher MELD scores and a poor prognosis [12].

This study was carried out to assess the prevalence of various types of anemia in cirrhotic patients and the distribution of the types of anemia in these patients. It also aimed to establish an association between anemia and the severity of liver disease, which could help us to assess our patients better and improve their management.

\section{Patients and methods}

This was a cross-sectional observational study carried out at a tertiary care hospital in Western India. The primary objective was to establish an association between the severity of liver cirrhosis, defined by the MELD score and Hb levels; secondary objectives were to examine the prevalence of various patterns of anemia in liver cirrhosis and assess the relation between macrocytosis and the severity of liver cirrhosis. A total of 181 patients admitted with a diagnosis of liver cirrhosis from January 2019 to April 2019 were enrolled in this study. Ethical clearance was obtained from the institutional ethics committee and all the participants gave written informed consent.

Inclusion criteria were: age $>18$ years; liver cirrhosis, irrespective of etiology; and $\mathrm{Hb}<13 \mathrm{~g} / \mathrm{dL}$ in males and $<12 \mathrm{~g} /$ $\mathrm{dL}$ in females.

Exclusion criteria were: patients who received blood transfusion in the past 3 months; those already on therapy for anemia; presence of chronic kidney disease; and any other etiology of anemia not attributable directly or indirectly to liver cirrhosis.

Liver cirrhosis was defined on the basis of clinical and radiological evidence, such as elastography and ultrasound. Complications, such as ascites, spontaneous bacterial peritonitis, hepatic encephalopathy, hepatorenal syndrome and upper GI bleeding, were also documented. Anemia was defined according to the World Health Organization's criteria ( $\mathrm{Hb}<13 \mathrm{~g} / \mathrm{dL}$ in males and $<12 \mathrm{~g} / \mathrm{dL}$ in females). A total of 181 patients who satisfied the inclusion and exclusion criteria were enrolled in the study.

All patients underwent thorough history taking and physical examination. Investigations included complete blood counts with platelets, mean corpuscle volume $(\mathrm{MCV}:<80 \mathrm{fL}=$ microcytic anemia, $>98 \mathrm{fL}=$ macrocytic anemia), peripheral blood smear for anemia typing, serum iron studies, serum B12 levels, liver function tests, including prothrombin time (INR), abdominal ultrasound, ascitic fluid analysis and upper GI endoscopy. MELD score was calculated using the formula $9.57 \times \log _{\mathrm{e}}($ creatinine $\mathrm{mg} / \mathrm{dL})+3.78 \times \log _{\mathrm{e}}$ (bilirubin $\mathrm{mg} / \mathrm{dL})+11.2 \times \log _{\mathrm{e}}(\mathrm{INR})+6.43$, where 6.43 is the constant for liver disease etiology. The Child-Turcotte-Pugh (CTP) score was also calculated for all the patients.

\section{Statistical analysis}

All patients were classified into 4 groups according to their anemia typing (microcytic, macrocytic, normocytic and dimorphic anemia). Patients were further subclassified according to their MELD scores (Group A $<12$ and Group B > 12) and CTP class (Child A, B and C). Univariate and multivariate linear regression analyses were used to examine the associations of the MELD score and CTP score with $\mathrm{Hb}$ levels and macrocytosis. Variables with a P-value $<0.05$ in univariate models were then included in the multivariate analyses. A 2-tailed test was used to calculate the P-value, and the results were considered statistically significant when the P-value was $<0.05$.

\section{Results}

\section{Patient characteristics}

Among the 181 patients enrolled 168 were males and 13 were females. The mean age was 49.7 years. Alcohol was the most common etiology (166 patients), followed by cryptogenic (12 patients), Budd-Chiari syndrome (2 patients) and hepatitis B (1 patient).

\section{Distribution of anemia types}

The mean Hb levels in males and females were $10.51 \mathrm{~g} / \mathrm{dL}$ and $10.48 \mathrm{~g} / \mathrm{dL}$, respectively. Macrocytosis (MCV>98 fL) was seen in $58(32 \%)$ patients. On anemia typing, a total of $93(51.4 \%)$ patients had normocytic normochromic anemia, 56 (30.9\%) had macrocytic anemia, $29(16.0 \%)$ had microcytic anemia and $3(1.7 \%)$ had dimorphic anemia (Table 1$)$.

Of the patients who had microcytic anemia on PBS, only 1 had iron-deficiency anemia (serum ferritin $<16 \mu \mathrm{g} / \mathrm{L}$ in males and $<10 \mu \mathrm{g} / \mathrm{L}$ in females). Of the patients who had macrocytic anemia on PBS, 29 had low serum B12 levels $(<220 \mathrm{ng} / \mathrm{mL})$.

\section{Macrocytosis and MELD score}

Of the 58 patients with macrocytosis, 45 (77.6\%) had a MELD score of $>12$, whereas only 13 (22.4\%) had a MELD score of $<12$. This difference was statistically significant $(\mathrm{P}<0.001)$. 


\section{Anemia and severity of liver cirrhosis}

Of the 181 patients, 63 were Child class A, 54 were Child B and 64 were Child $\mathrm{C}$. $\mathrm{Hb}$ values were highest for Child $\mathrm{A}$, followed by $\mathrm{B}$ and then $\mathrm{C}$ (Fig. 1). There was a statistically significant correlation between CTP class and $\mathrm{Hb}(\mathrm{P}<0.001)$ (Table 2). The Pearson correlation coefficient between $\mathrm{Hb}$ and MELD score was significant $(\mathrm{P}<0.001)$ (Table 3, Fig. 2). In addition, there was a significant association between MELD score and serum B12 levels $(\mathrm{P}=0.02)$; only a quarter of the patients with a high MELD score were deficient in Vit B12 (Table 4).

\section{Discussion}

In our study, $51.4 \%$ of the patients had normocytic normochromic anemia, 30.9\% had macrocytic anemia, 16.0\% had microcytic anemia and $1.7 \%$ had dimorphic anemia. Irondeficiency anemia, based on MCV and low serum ferritin levels, was seen only in 1 of 29 patients who had microcytic anemia on PBS. However, the interpretation of routine lab parameters such as serum ferritin is extremely difficult in liver cirrhosis, and bone-marrow staining for iron with Prussian blue is required for the confirmation of the diagnosis.

A total of 58 patients had macrocytosis (MCV $>98 \mathrm{fL})$; of these, 56 had macrocytic anemia on PBS and 2 had dimorphic anemia. The remaining $51.4 \%$ of patients had normocytic normochromic anemia, the most common type of anemia encountered in liver cirrhosis, attributable to the chronic inflammatory state. We also found a significant correlation between MELD score and macrocytosis.

In our study there was a significant correlation between the MELD score and $\mathrm{Hb}$ levels. Lower $\mathrm{Hb}$ levels were associated with a higher MELD score. Similar findings were seen in a study conducted by Scheiner et al, where anemic patients showed a higher MELD ( $12 \pm 4$ vs. $9 \pm 3 ; \mathrm{P}<0.001)$ [12]. In a study conducted by Jain et al, 88 patients with alcoholic liver cirrhosis were divided into 5 groups according to their MELD scores. It

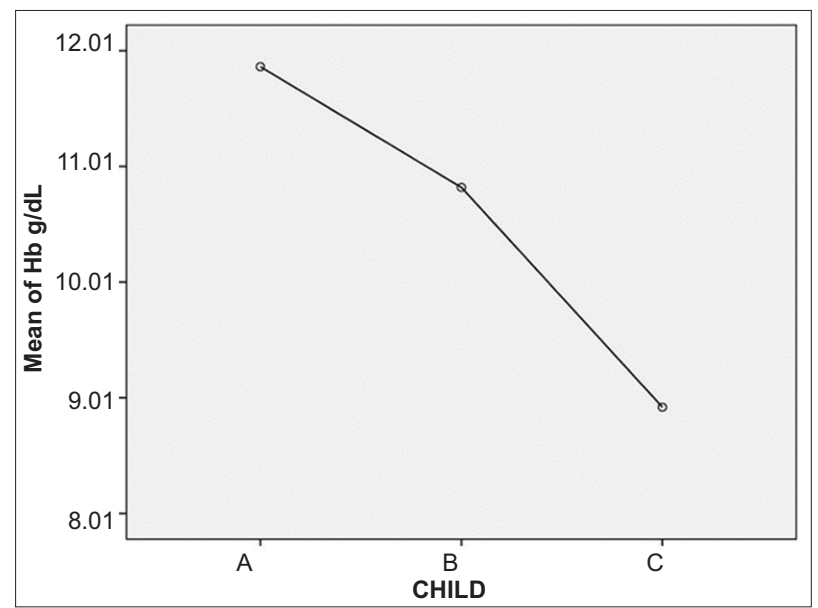

Figure 1 Mean plot depicting correlation between average hemoglobin $\mathrm{Hb}$ ) and Child-Turcotte-Pugh class was found that hematological abnormalities, such as anemia and leucopenia, were more common in the higher MELD score group [13]. Studies have shown that anemia is a poor prognostic factor in patients with liver cirrhosis, and the severity of anemia increases with the stage of liver disease $[14,15]$.

We also found a statistically significant correlation between CTP class and Hb. Patients with Child C classification had lower $\mathrm{Hb}$ levels compared to those with Child A or B.

Table 1 Demographic profile

\begin{tabular}{|c|c|}
\hline Demographic details & \\
\hline Mean age & 49.7 yrs. \\
\hline Male:female ratio & 13:1 \\
\hline $\begin{array}{l}\text { Etiology } \\
\text { Alcohol } \\
\text { Cryptogenic } \\
\text { Budd-Chiari syndrome } \\
\text { Hepatitis B }\end{array}$ & $\begin{array}{c}\text { Frequency } \\
166 \\
12 \\
2 \\
1\end{array}$ \\
\hline $\begin{array}{l}\text { Mean } \mathrm{Hb}(\mathrm{g} / \mathrm{dL}) \\
\text { Males } \\
\text { Females }\end{array}$ & $\begin{array}{l}10.51 \\
10.48\end{array}$ \\
\hline $\begin{array}{l}\text { Mean corpuscular volume }(\mathrm{MCV}) \\
\text { Normocytosis }(80-98 \mathrm{fL}) \\
\text { Microcytosis }(<80 \mathrm{fL}) \\
\text { Macrocytosis }(>98 \mathrm{fL})\end{array}$ & $\begin{array}{c}\text { Frequency } \\
111 \\
12 \\
58\end{array}$ \\
\hline Mean MCV of study group & $90.3 \mathrm{fL}$ \\
\hline $\begin{array}{l}\text { Distribution of anemia } \\
\text { Normocytic normochromic } \\
\text { Macrocytic } \\
\text { Microcytic } \\
\text { Dimorphic }\end{array}$ & $\begin{array}{c}93(51.4 \%) \\
56(30.9 \%) \\
29(16.0 \%) \\
3(1.7 \%)\end{array}$ \\
\hline $\begin{array}{l}\text { Child-Turcotte-Pugh class } \\
\text { A } \\
\text { B } \\
\text { C }\end{array}$ & $\begin{array}{l}\text { Frequency } \\
\qquad 3 \\
54 \\
64\end{array}$ \\
\hline $\begin{array}{l}\text { MELD score } \\
\text { Group A }(\text { MELD }<12) \\
\text { Group B }(\text { MELD>12) }\end{array}$ & $\begin{array}{c}114 \\
67\end{array}$ \\
\hline
\end{tabular}

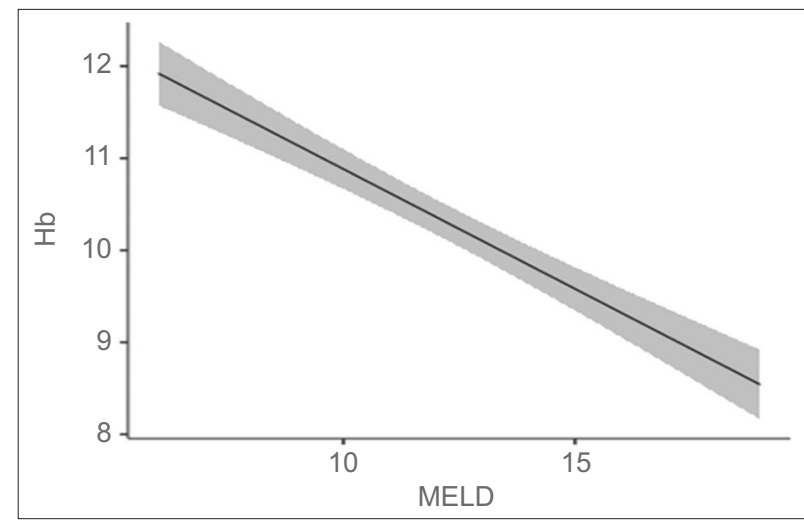

Figure 2 Marginal means plot of linear regression analysis showing negative correlation between hemoglobin $(\mathrm{Hb})$ levels and model for end-stage liver disease $($ MELD) score $(\mathrm{P}<0.001)$ 
Table 2 Association of Child-Turcotte-Pugh (CTP) class with decreased hemoglobin levels

\begin{tabular}{lccccc}
\hline $\begin{array}{l}\text { CTP } \\
\text { class }\end{array}$ & $\begin{array}{c}\text { Number of } \\
\text { patients }\end{array}$ & $\begin{array}{c}\text { Mean hemoglobin } \\
\text { in }(\mathrm{g} / \mathrm{dL})\end{array}$ & $\begin{array}{c}\text { Standard } \\
\text { deviation }\end{array}$ & Standard error & $\begin{array}{c}\text { P-value (for difference in } \\
\text { means using ANOVA) }\end{array}$ \\
\hline $\mathrm{A}$ & 63 & 11.86 & 1.29533 & 0.16320 & $<0.001$ \\
$\mathrm{~B}$ & 54 & 10.82 & 1.63154 & 0.22202 & \\
$\mathrm{C}$ & 64 & 8.92 & 1.15207 & 0.14401 & \\
\hline Total & 181 & 10.51 & 1.84250 & 0.13695 & \\
\hline
\end{tabular}

Table 3 Linear regression analysis for MELD and anemia

Linear regression model coefficients

\begin{tabular}{|c|c|c|c|c|c|c|}
\hline \multirow[t]{2}{*}{ Predictor } & \multirow[t]{2}{*}{ Estimate } & \multirow[t]{2}{*}{ SE } & \multicolumn{2}{|c|}{$\begin{array}{c}95 \% \text { confidence } \\
\text { interval }\end{array}$} & \multirow[t]{2}{*}{$\mathrm{t}$} & \multirow[t]{2}{*}{ P-value } \\
\hline & & & Lower & Upper & & \\
\hline Intercept & 13.483 & 0.3073 & 12.877 & 14.090 & 43.9 & $<0.001$ \\
\hline MELD & -0.260 & 0.0241 & -0.308 & -0.213 & -10.8 & $<0.001$ \\
\hline
\end{tabular}

SE, standard error; $M E L D$, model for end-stage liver disease

Table 4 Correlation between Vit B12 levels and MELD score

\begin{tabular}{lccc}
\hline \multirow{2}{*}{ MELD } & \multicolumn{2}{c}{ Vitamin B12 levels $(\mathrm{ng} / \mathrm{mL})$} & \multirow{2}{*}{ Total } \\
\cline { 2 - 3 } & More than 200 & Less than 200 & \\
\hline MELD $<12$ & 100 & 14 & 114 \\
MELD $>12$ & 50 & 17 & 67 \\
Total & 150 & 31 & 181 \\
\hline
\end{tabular}

Chi Square $=5.10$. P-value $=0.0240$

$M E L D$, model for end-stage liver disease

Macrocytosis and macrocytic anemia are associated with the severity of liver disease. In a study conducted by Yang et al, macrocytic anemia was associated with the severity of liver disease in patients with decompensated cirrhosis related to hepatitis B [16]. The MELD score was used to assess the severity of liver disease in this study. In another study conducted by Yoon et al, elevated MCV levels were associated with greater liver cancer mortality in men [17].

Of the 58 patients who had macrocytosis, only 29 had low serum B12 levels. Acute and chronic liver disease is associated with higher serum B12 levels, and this has been attributed to the release of vitamin B12 from the liver as a result of hepatocellular necrosis and increased binding of B12 with serum proteins [18]. In addition, higher B12 levels are associated with severe liver disease and prognosis.

In conclusion, in our study we found a significant correlation between the MELD score and the degree of anemia. A higher MELD score was associated with more severe hematological complications. Whether the correction of anemia in such patients at an early stage will retard the progression of disease is debatable and requires further studies. However, lower $\mathrm{Hb}$ levels were definitely associated with more severe forms of liver cirrhosis, as was established by the correlations with
MELD score and CTP class in this study. Larger studies will be needed to assess whether $\mathrm{Hb}$ should be used as a marker for the severity of liver disease. The reverse is also true: MELD score can be used effectively to predict hematological complications in such patients.

\section{Summary Box}

\section{What is already known:}

- Anemia in liver cirrhosis is multifactorial and the most common complication encountered

- Hemoglobin levels decrease with an increase in the severity of liver disease

- Macrocytosis is also associated with greater severity of liver disease

\section{What the new findings are:}

- In this study there was a significant negative correlation between model for end-stage liver disease (MELD) score and hemoglobin levels

- Child-Turcotte-Pugh (CTP) scores also showed that hemoglobin levels were significantly lower in CTP class $\mathrm{C}$ patients

- Macrocytosis was significantly higher in patients with MELD scores $>12$

\section{References}

1. McHutchison JG, Manns MP, Longo DL. Definition and management of anemia in patients infected with hepatitis $C$ virus. Liver Int 2006;26:389-398.

2. Caldwell SH, Hoffman M, Lisman T, et al; Coagulation in Liver Disease Group. Coagulation disorders and hemostasis in liver disease: pathophysiology and critical assessment of current management. Hepatology 2006;44:1039-1046.

3. Pereira SP, Langley PG, Williams R. The management of abnormalities of hemostasis in acute liver failure. Semin Liver Dis 1996;16:403-414.

4. Gonzalez-Casas R, Garcia-Buey L, Jones EA, Gisbert JP, MorenoOtero R. Systematic review: hepatitis-associated aplastic anaemia - a syndrome associated with abnormal immunological function. Aliment Pharmacol Ther 2009;30:436-443. 
5. Weiss G, Goodnough LT. Anemia of chronic disease. N Engl J Med 2005;352:1011-1023.

6. Camaschella C. Iron-deficiency anemia. $N$ Engl $J$ Med 2015;373:485-486.

7. Nunnally RM, Levine I. Macronormoblastic hyperplasia of the bone marrow in hepatic cirrhosis. Am J Med 1961;30:972-975.

8. Silber R, Amorosi E, Lhowe J, Kayden HJ. Spur-shaped erythrocytes in Laennec's cirrhosis. N Engl J Med 1966;275:639-643.

9. Cooper RA, Diloy Puray M, Lando P, Greenverg MS. An analysis of lipoproteins, bile acids, and red cell membranes associated with target cells and spur cells in patients with liver disease. J Clin Invest 1972;51:3182-3192.

10. Malinchoc M, Kamath PS, Gordon FD, Peine CJ, Rank J, ter Borg PC. A model to predict poor survival in patients undergoing transjugular intrahepatic portosystemic shunts. Hepatology 2000;31:864-871.

11. Freeman RB, Wiesner RH, Edwards E, Harper A, Merion R, Wolfe R; United Network for Organ Sharing Organ Procurement and Transplantation Network Liver and Transplantation Committee. Results of the first year of the new liver allocation plan. Liver Transpl 2004;10:7-15.

12. Scheiner B, Semmler G, Maurer F, et al. Prevalence of and risk factors for anaemia in patients with advanced chronic liver disease. Liver Int 2020;40:194-204.

13. Jain D, Aggarwal HK, Rao A, Dahiya S, Singla S. Hematological spectrum in patients with alcoholic liver cirrhosis: a model of end-stage liver disease score based approach. Int J Adv Med 2016;3:234-240.

14. Mathurin SA, Agüero AP, Dascani NA, et al. Anemia in hospitalized patients with cirrhosis: prevalence, clinical relevance and predictive factors. Acta Gastroenterol Latinoam 2009;39:103-111.

15. Qamar AA, Grace ND, Groszmann RJ, et al; Portal Hypertension Collaborative Group. Incidence, prevalence, and clinical significance of abnormal hematologic indices in compensated cirrhosis. Clin Gastroenterol Hepatol 2009;7:689-695.

16. Yang J, Yan B, Yang L, et al. Macrocytic anaemia is associated with the severity of liver impairment in patients with hepatitis B virusrelated decompensated cirrhosis: a retrospective cross-sectional study. BMC Gastroenterol 2018;18:161.

17. Yoon HJ, Kim K, Nam YS, Yun JM, Park M. Mean corpuscular volume levels and all-cause and liver cancer mortality. Clin Chem Lab Med 2016;54:1247-1257.

18. Stevenson TD, Beard MF. Serum vitamin B12 content in liver disease. N Engl J Med 1959;260:206-210. 